\title{
A BOA-FÉ NA FORMAÇÃo dOS CONTRATOS*
}

\author{
Antonio Junqueira de Azevedo \\ Professor Titular do Departamento de Direito Civil \\ da Faculdade de Direito da USP \\ Diretor da Faculdade de Direito da Universidade de São Paulo
}

Resumo:

O presente trabalho foi elaborado para as jornadas de Luisiana, da Associação Henri Capitant, em 1992, respondendo a questionário previamente distribuído.

A utilização da noção de boa-fé no direito brasileiro se dá principalmente através da chamada boa-fé subjetiva. O princípio da boa-fé não está formulado como regra geral no direito brasileiro. A boa-fé subjetiva aparece, porém, em muitos artigos específicos do Código Civil. A mudança de mentalidade surge no recente Código de Proteção ao Consumidor (Lei n. 8.078, de 1990) com a clara introdução da boa-fé objetiva como regra de conduta.

As conseqüências da falta de boa-fé na formação do contrato, quando este não é concluído em conseqüência da ruptura das tratativas, somente existem, no direito brasileiro, quando se pode falar em dolo ou culpa. Exame das situações em que o contrato é concluído mas anulável por vício e dos casos em que o dolo ou a coação não são determinantes do negócio.

O conteúdo concreto da chamada obrigação de boa-fé na fasé de formação contratual. Há, no direito brasileiro, regras específicas sobre o dever de informar, mas não, sobre o dever de confidencialidade e sobre como agir durante a negociação.

As sanções no caso de o contrato não ser concluído, no de ser concluído mas em seguida anulado por força de vício de formação, e no de ser concluído e mantido, apesar de haver vício.

A questão da oferta, que é vinculante, no direito brasileiro e a modificação ocorrida com o Código de Proteção ao Consumidor. O précontrato no Direito brasileiro e sua grande freqüência nos casos de venda de imóveis.

* Este trabalho constitui o relatório brasileiro sobre boa-fé na formação dos contratos para as "Journées Louisianaises" de 1992, da Association Henri Capitant, e foi feito pelo autor após receber consideraçōes escritas sobre o mesmo tema, do prof. Alcides Tomasetti Jr. 
Os tribunais superiores e a questão da boa-fé. Considerações finais acerca do princípio da boa-fé objetiva e como deve ser considerada pelo juiz na fase de formação contratual. Sugestão de um princípio de distribuição eqüitativa dos prejuizos para casos de danos que não se enquadram adequadamente quer na responsabilidade contratual quer na extracontratual ou aquiliana.

Abstract:

The present work was made for the Louisiana Journeys of the Henri Capitant Association in 1992, in answer to a questionnaire previously distributed.

The use of the notion of good faith in Brazilian Law is done mainly through he so called subjective good faith. The principle of good faith is not formulated as a general rule in Brazilian law. Subjective good faith, though, appears in many specific sections of the Civil Code. The change in mode of thought appears in the recent Consumer Protection Code (Law n. 8.078, of 1990) with the clear introduction of the objective good faith as a rule of behavior.

The consequences of the lack of good faith in the formation of the contract when it is not concluded as a consequence of a rupture in the dealings, only exist in the Brazilian law when it is possible to speak in deceitfulness or fault. Examination of the situations in wich the contract is concluded but voidable by defect and of the cases in which the deceitfulness or the coercion are not determinants of the business.

The tangible content of the so called liability of good faith in the contractual formation phase. There are, in Brazilian Law, specific rules about the duty to inform, but not, about the duty of confidentiality and about how to act during negotiations.

The sanctions in the event of the contract not being concluded, in the event of being concluded but soon after made void due to defect of formation and in the event of being concluded and maintained, in spite of the existence of defect.

The question of the offer that is binding in Brazilian law and the modification introduced with the Consumer Protection Code. The precontract in Brazilian law and its great recurrence in situations of sale of real estate.

The superior courts and the question of good faith. Final considerations about the principle of objective good faith and how it should be considered by the judge in the contract formation phase. Suggestion of a principle of equitative distribution of losses for cases of damage that do not fit in adequately in contractual responsability, in the extra contractual or Aquilian. 


\section{A utilização da noção de boa-fé no direito brasileiro}

1.1. No direito brasileiro, a boa-fé nas relações entre particulares é um princípio jurídico mas não está formulado como regra de aplicação geral. No Código Civil, elaborado sob o influxo das idéias pandectistas da segunda metade do século passado e cuja vigência se iniciou em $1^{9}$ de janeiro de 1917, não há regra genérica que se refira expressamente à boa-fé na formação ou execução dos contratos como as dos artigos ou parágrafos 1.134 do Código Civil francês, 242 do B.G.B., 1.337 do Código Civil italiano e 227, do Código Civil português.

Há, nessa omissão do Código Civil brasileiro, um reflexo da mentalidade capitalista da segunda metade do século XIX, mais preocupada com a segurança da circulação e desenvolvimento das relações jurídicas do que com a justiça material dos casos concretos, porque a verdade é que o Código Comercial brasileiro, muito anterior ao Código Civil (o Código Comercial é de 1850), já tinha regra genérica sobre a boa-fé é o art. 131, sobre interpretação contratual.

Em assuntos específicos, como contrato de seguro, contrato de sociedade (art. 1.404), aquisição a non domino (art. 622), pagamento indevido (art. 968), posse (art. 490 e ss.), usucapião (art. 500 e ss.), construção e plantação (art. 546 e ss.), dívida de jogo (art. 1.677), etc., o próprio Código Civil prevê a boa-fé para certas conseqüências jurídicas. Trata-se, porém, em todos esses casos, salvo os dois primeiros (seguro e sociedade), da chamada boa-fé subjetiva, isto é, daquele estado interior ou psicológico relativo ao conhecimento, ou desconhecimento, e a intenção, ou falta de intenção, de alguém.

Vale dizer, ainda, que, atualmente, como conseqüência da mudança de mentalidade, a recente lei de proteção ao consumidor, que, por sua amplitude, é denominada Código de Proteção do Consumidor (Lei no 8.078, de 1990) tem o princípio da boa-fé refletido em inúmeros de seus artigos. Aqui, trata-se, na verdade, da boa-fé objetiva que interessa à formação do contrato, isto é, a boa-fé como regra (objetiva) de conduta.

1.2 .

Especificamente, por ocasião das tratativas e negociações que levam à conclusão do contrato, é importante salientar, desde já mas para desenvolvimento posterior - que, no direito brasileiro, há regra expressa segundo a qual a oferta de contrato obriga o proponente. Todavia, fora da questão da 
oferta e, evidentemente, de eventuais convenções expressas das partes sobre as negociações, os tribunais brasileiros não reconhecem qualquer vínculo obrigacional entre os pré-contratantes. A ruptura das negociações ou o arrependimento, antes da conclusão do contrato, são, pois, livres.

A relação entre os pré-contratantes somente terá eficácia jurídica pelo lado negativo ou patológico, da culpa ou dolo, isto é, somente pelo lado do dever de não se comportar de forma socialmente condenável. Esse dever, e não, obrigação, é sancionado pela ação de indenização do art. 159, do Código Civil.

Tanto nas tratativas quanto no momento da conclusão do contrato, a situação no Brasil é encarada, pois, na verdade, pelo lado de má-fé, isto é, o entendimento é o de que somente é responsável por perdas e danos aquele que agiu de má-fé na fase de formação contratual. Na verdade, ainda aqui, trata-se, pois, de um aspecto da boa-fé subjetiva.

Esse entendimento é extraordinariamente facilitado pela regra do art. 159, do Código Civil, sobre o ato ilícito, que é de amplidão pouco comum nas legislações dos demais países. Esta regra, conhecida por todo e qualquer jurista ou simples estudante de direito, prescreve que todo aquele que, por ação ou omissão voluntária, por negligência ou imprudência, causar prejuízo ou violar direito, fica obrigado a reparar o dano. Ela é, no campo do direito privado, a expressão legal do princípio geral de direito, de respeito ao próximo e a seus bens (do alterum non laedere, isto é, princípio do respeito, ou segundo princípio de direito de Ulpiano e dos estóicos). A indenização será cabal e, naturalmente, como a responsabilidade é aquiliana ou extracontratual, a prova do dolo ou culpa cabe ao autor da ação e a prescrição é a dos atos ilícitos.

\section{Conseqüência da falta da boa-fé na formação do contrato}

2.1. Quando o contrato não foi concluído, em conseqüência da ruptura das tratativas ou das negociações preliminares, pode-se, portanto, obter indenização por ato ilícito, alegando comportamento desleal ou abusivo. Faz-se, então, muitas vezes, referência à teoria de Von Jhering sobre a culpa in contrahendo. Fora da hipótese de ato ilícito e sempre deixando de lado a questão da oferta e de eventuais convenções expressas entre as partes sobre as 
negociações a ruptura unilateral ou o arrependimento são absolutamente livres. Se a ruptura se dá com alguma causa, sem culpa, não há responsabilidade pelos danos causados a outra parte; o direito brasileiro, não tendo regra geral de boafé na formação dos contratos, essa espécie de "noção aberta", dirigida antes ao juiz que à parte, não permite ao juiz fixar uma indenização.

2.2. Se o contrato é concluído mas é anulável por vício, o legitimado para a ação - por exemplo, o enganado por dolo principal ou pede a anulação ou não pede. Se não pede, não há nenhuma conseqüência, isto é, se o interessado optou pela manutenção do contrato, não pode simultaneamente pedir qualquer indenização pela má-fé da parte contrária. Se pede, a sentença de desconstituição tem eficácia retroativa ex tunc, há a restituição das partes ao estado que antes do contrato se achavam e, não sendo isto possível, há indenização do equivalente (art. 158, do Código Civil). Além da volta ao statu quo ante, o legitimado pode cumulativamente, com fundamento no art. 159 do Código Civil, pedir perdas e danos pelo ato ilícito de tudo que não recuperou com a anulação.

2.3.

Entretanto, o que há de mais interessante é que, quando o dolo ou a coação não são determinantes do negócio - e, portanto, se referem a ponto secundário -, o negócio não é anulável, mas o prejudicado, mesmo assim, pode pedir perdas e danos, por ato ilícito do causador do prejuízo.

\section{Conteúdo concreto da chamada obrigação de boa-fé na fase de formação contratual}

3.1.

O princípio da boa-fé na formação contratual pode se refletir numa regra genérica o que, como vimos, não existe no direito brasileiro mas pode também se desdobrar em regras específicas: dever de informar a contraparte, dever de manter sigilosas as conversações, dever de avisar imediatamente quando perder interesse no negócio, etc.

Uma regra sobre o dever de informar sobre fato ou qualidade essencial somente existe no direito brasileiro a contrario sensu do art. 94, do Código Civil, que determina ser a omissão dolosa causa de anulabilidade. $\mathrm{O}$ citado artigo prescreve: "Nos atos bilaterais, o 'silêncio' intencional de uma das 
partes a respeito de fato ou qualidade que a outra parte haja ignorado, constitui omissão dolosa, provando-se que sem ela se não teria celebrado o contrato".

$\mathrm{O}$ dever de informar existe, expressamente, também no contrato de seguro (arts. 1.443 a 1.446, do Código Civil). Essa regra existe desde 1916, mas observamos que, neste caso, como na regra expressa sobre o caráter vinculante da oferta, a existência da norma torna praticamente inútil o apelo a uma possível regra genérica de comportamento de boa-fé.

Atualmente, no Código de Proteção do Consumidor, há várias regras impondo o dever de informar; assim, o art. 60, entre os "direitos básicos" do consumidor, inclui o direito "à informação adequada e clara sobre os diferentes produtos e serviços, com especificação correta de quantidade, características, composição, qualidade e preço; bem como sobre os riscos que apresentam". Há, ainda, todo um capítulo (Capítulo V) Das práticas comerciais, com exigência de veracidade na oferta (Seção II) e na publicidade (Seção III).

Por outro lado, uma regra sobre o dever de confidencialidade sobre as informações obtidas da outra parte não existe, infelizmente, na legislação brasileira. Esse dever, salvo nos casos óbvios de sigilo profissional, não é sequer caracterizado na jurisprudência e na doutrina. Os casos concretos terão que obter solução com fundamento legal no art. 159, do Código Civil e no conseqüente dever genérico de bom comportamento.

3.3. Outras regras específicas sobre como agir durante a negociação e a conclusão do contrato não existem. O Código de Proteção do Consumidor, porém, estabelece quais as "práticas abusivas" (arts. 39 a 41), entre as quais a seguinte:

"Artigo 39 - É vedado ao fornecedor de produtos ou serviços:

IV - prevalecer-se da fraqueza ou ignorância do consumidor, tendo em vista sua idade, saúde, conhecimento ou condição social, para impingir-lhe seus produtos ou serviços". 
A distinção entre obrigação de meio e de resultado, embora conhecida, não é adotada na legislação brasileira, não trazendo, portanto, nenhuma diferença para o que ficou escrito até aqui.

\section{Sanções}

4.1.

A sanção, no direito brasileiro, visa repor o prejudicado na exata situação que tinha antes do fato causador do prejuízo. Segue-se daí que, se o contrato não foi concluído e há possibilidade de se caracterizar a ruptura das negociações como ato ilícito (art. 159, do Código Civil), as perdas e danos incluirão tudo que a parte lesada perdeu (damnum emergens) e tudo que razoavelmente deixou de lucrar (lucrum cessans). "O que razoavelmente deixou de lucrar" não é, naturalmente, o que obteria com o contrato, e sim, o que obteria se as negociações não fossem realizadas. No direito brasileiro, por outro lado, não se adota nem a expressão nem o conceito de "interesse negativo" do direito alemão.

4.2.

Se o contrato é concluído e, em seguida, anulado por força de vício de formação, devolve-se tudo o que se recebeu e, não sendo isso possível, o equivalente. Ademais, se há prejuízos não cobertos pela simples volta ao statu quo ante, há possibilidade, caracterizado o ato ilícito, de pedir o que falta com fundamento no art. 159, do Código Civil.

4.3.

Se o contrato é concluído e mantido, porque o vício não é essencial, portanto, o contrato não é anulável, como já foi dito (n. 2.3., supra) pode-se pedir perdas e danos pelas piores condições em que o negócio foi feito (cf. art. 93, do Código Civil, para o dolo acidental).

4.4.

Observamos que, no direito brasileiro, o dolo de terceiro, desconhecido da parte a quem aproveita, não leva à anulação mas o prejudicado tem ação de perdas e danos contra o terceiro pelo art. 159, do Código Civil. Por sua vez, a coação de terceiro, diferentemente, mesmo desconhecida da parte a quem aproveita, leva à anulação, mas, aí, é o que vê o contrato anulado que tem ação de perdas e danos contra o terceiro.

4.5.

Num caso, a sanção chega a ser curiosa: se as duas partes agiram com dolo, a sanção é ... a validade do contrato! (art. 97, do Código Civil: 
"Se ambas as partes procederam com dolo, nenhuma pode alegá-lo, para anular o ato, ou reclamar indenização").

4.6. Em qualquer hipótese de indenização, o quantum é fixado objetivamente segundo o montante dos prejuízos ou pela cláusula de pré-fixação de perdas e danos. Não se aumenta ou diminui o quantum de acordo com o dolo ou o grau de culpa do agente. Em caso de necessidade, o juiz recorre a arbitramento, socorrendo-se de peritos.

\section{A questão da oferta}

Ao contrário do ordenamento jurídico de outros países, o brasileiro não precisa se socorrer do princípio da boa-fé para solucionar o problema da retirada da oferta antes da aceitação. $O$ art. 1.080, do Código Civil, dispõe: "A proposta de contrato obriga o proponente, se o contrário não resultar dos termos dela, da natureza do negócio ou das circunstâncias do caso". A existência da regra torna dispensável a alegação da boa-fé objetiva.

Embora haja, no campo de prova, como é evidente, alguma dificuldade para caracterizar a oferta vinculante, pode-se dizer tecnicamente que o ofertante, por ato unilateral, cria, no patrimônio do oblato, um direito expectativo, ou potestativo, de concluir o contrato. Isto é especialmente claro nos casos de oferta irrevogável ou com prazo determinado de eficácia. Segue-se daí que a retirada da oferta acarreta responsabilidade obrigacional, isto é, nãoaquiliana.

Observamos, porém, que a obrigação que surge da oferta não tem o efeito próprio de vincular o ofertante ao futuro contrato, se a retirada da oferta se dá antes da aceitação. A obrigação se converte em perdas e danos.

Já o Código de Proteção do Consumidor, diferentemente, dá eficácia plena à oferta. Segundo o art. 35, e se assim quiser o consumidor, o fornecedor ficará sujeito ao cumprimento forçado nos termos da oferta (e, ademais, equipara-se à oferta a publicidade ou a apresentação para consumo de bens e serviços). 


\section{O pré-contrato}

No direito brasileiro, as negociações preliminares não se confundem, de forma alguma, com o pré-contrato. Aquelas, como já dito, são tratadas sob a ótica da chamada responsabilidade extracontratual do art. 159, do Código Civil, enquanto o pré-contrato é contrato; cria vínculo jurídico obrigação - entre as partes, antes mesmo de qualquer inadimplemento.

O pré-contrato é comuníssimo no Brasil. Em $99,99 \%$ dos casos de vendas de imóveis, antes do contrato definitivo, é feito um pré-contrato, dito "compromisso" ou "promessa" de venda-e-compra, com previsão do pagamento do preço em parcelas (e a escritura pública de venda-e-compra somente é feita após o pagamento integral do preço).

Todos os pré-contratos tem execução específica (art. 639 do Código de Processo Civil: "Se aquele que se comprometeu a concluir um contrato não cumprir a obrigação, a outra parte, sendo isso possivel e nāo excluído pelo título, poderá obter uma sentença que produza o mesmo efeito do contrato a ser firmado"). Alguns têm, até mesmo, ação própria, por exemplo, a adjudicação compulsória para os compromissos de venda-e-compra de imóveis.

\section{A boa-fé e os Tribunais Superiores}

O Supremo Tribunal Federal tem no Brasil, atualmente (Constituição da República Federativa do Brasil, que é de 1988), competência especialmente voltada para o controle constitucional de leis, atos e decisões; não é, portanto, um tribunal semelhante à Cour de Cassation francesa. De resto, a constitucionalidade de nossas leis não é examinada previamente fora do Poder Legislativo.

Abaixo do Supremo Tribunal Federal, há o Superior Tribunal de Justiça que, através de "recurso especial", examina questōes de direito, e não, propriamente, questões de fato, nos processos já decididos pelos tribunais inferiores. Segue-se do exposto que, como a boa-fé é, normalmente, questão de fato, dificilmente é ela examinada nos dois tribunais superiores. Todavia, esse exame pode ocorrer desde que, com muita argúcia, se demonstre que, previamente, há um problema de qualificação jurídica na matéria decidida na instância inferior. 


\section{Autonomia privada e princípio da boa-fé}

A doutrina e a jurisprudência brasileiras não têm se dedicado à importante questão de saber quais os limites da autonomia privada na eliminação ou atenuação das conseqüências do princípio da boa-fé. Procurando interpretar o "espírito do direito brasileiro" - atividade perigosa parece-nos, em primeiro lugar, que são nulas todas as convenções ou cláusulas que visem diretamente eliminar, ou simplesmente diminuir, a exigência de boa-fé na formação e execução dos contratos. Antes mesmo do Código Civil, já se dizia que eram nulas todas as condições contrárias aos bons costumes e à ordem pública; as noções de bons costumes e ordem pública, apesar da sua imprecisão, integram o ordenamento jurídico brasileiro (cf. art. 17, da Lei de Introdução ao Código Civil). São ilícitos como contrários à lei os atos contrários aos bons costumes e à ordem pública; as convenções ou cláusulas que visem eliminar ou diminuir a boa-fé estão nesse caso.

Por outro lado, são válidas, porque, em princípio, não constituem nenhuma autorização para agir ilicitamente, as convenções ou cláusulas de não indenizar e as convenções ou cláusúlas que limitam a indenização (por exemplo, cláusula de pré-fixação de perdas e danos). Aqui, salvo algumas hipóteses específicas (no contrato de transporte, por exemplo, as cláusulas de não indenizar são nulas - Súmula n. 161 do STF), o acordo tem validade; seria o caso de uma convenção feita ao se iniciarem as negociações, segundo a qual qualquer das partes, a qualquer momento, poderia romper as negociações sem responsabilidade por perdas e danos.

A conclusão que se tira dos dois parágrafos anteriores é que a responsabilidade extracontratual por ato doloso é inafastável, eis que a cláusula de não indenizar não autoriza a prática do ato ilícito, mas essa mesma responsabilidade pode ser eliminada no caso do ato culposo.

\section{Considerações finais}

Síntese: $\quad$ o princípio da boa-fé quer no seu aspecto subjetivo quer no objetivo de regra de comportamento tem, na formação dos contratos, grande aplicação na vida prática do povo brasileiro; uma verificação sociológica mostraria facilmente que as expressões boa-fé e má-fé são as mais usadas quando 
alguém comenta com outrem um negócio feito. No campo jurídico, porém, deixando de lado a questão da má-fé que, no fundo, diz respeito à boa-fé subjetiva, cumpre dizer que, quanto à boa-fé objetiva, como regra de comportamento, não há disposição expressa nó direito brasileiro sobre a formação contratual (nem mesmo sobre execução contratual). Novas leis, especialmente a Constituição da República (1988) e o Código de Proteção do Consumidor (1990), revelam, todavia, um aumento do número de disposiçôes que se referem explicitamente à boa-fé objetiva.

19 Conclusão: Há, como se sabe, entre um princípio jurídico, que é uma idéia ordenadora, e as regras jurídicas em que ele se reflete, uma certa distância na ordem de abstração intelectual; é uma distância semelhante a que vai, por sua vez, da regra jurídica ao caso concreto. Do caso à regra e da regra ao princípio, sobe à mente em duas etapas (e três patamares); ganha-se em descortínio o que se perde em concretitude. Inversamente, uma vez adquirido o princípio, desce o aplicador do direito, do princípio, à regra e, da regra, ao caso. Ora, com o princípio da boa-fé não pode ser diferente; segue-se daí que, para seu melhor desenvolvimento na formação contratual, é indispensável seu desdobramento em regras, como na determinação do dever de informar, na de não revelar o que se soube durante a fase preliminar, na de indenizar os prejuízos causados pela ruptura das negociações. É essa espécie de desenvolvimento que acreditamos estar ocorrendo atualmente no direito brasileiro. Todavia, à medida que as regras vão sendo formuladas, os operadores do direito já não precisam apelar para o princípio da boa-fé, que passa a ser ratio legis, e não, lex.

2a Conclusão: Na questão específica da ruptura das negociações, antes que discutir se a responsabilidade é aquiliana ou contratual, talvez fosse preferível optar por uma terceira responsabilidade relativa à distribuição equitativa dos prejuizos. A responsabilidade aquiliana fundamenta-se no princípio do respeito (alterum non laedere) e, portanto, tem, no caso, dois excessos, ou dois inconvenientes: exige a prova da culpa o que é difícil e dá direito a uma reparação integral (o que pode ser muito). A responsabilidade contratual, por sua vez, fundamenta-se no princípio da palavra dada (da fides, o terceiro princípio geral de direito dos estóicos) não exige a prova da culpa mas, em 
compensação, não parece adequada às negociações preliminares quando as partes ainda "não se contrataram".

3a Conclusão: Uma regra genérica de boa-fé na formação contratual parece ser útil como noção aberta da qual o juiz pode se valer, mas há nisto uma incongruência: a mesma imprecisão que facilita a decisão é inconveniente para as partes. Como obedecer à uma regra imprecisa? Parece, portanto, que, ao lado de regras específicas, seria melhor admitir, não uma regra genérica de boa-fé na formação contratual, mas sim, uma norma supletiva que fixasse os pressupostos de uma possível indenização, assim: diante da confiança criada e prejuízos sofridos, diante da relação de causa e efeito entre negociação e prejuízo (nexo de causalidade) e diante da ausência de má-fé do prejudicado - três pressupostos - o juiz arbitra um quantum de indenização. A responsabilidade pelos danos resultantes de fatos na formação contratual, à semelhança de outros casos de responsabilidade não fundada na culpa (princípio do respeito), nem no inadimplemento (princípio da fides), estaria fundada no princípio maior, de solidariedade social, que justifica a distribuição equitativa dos prejuízos. 